J. Lake Sci. (湖泊科学), 2015, 27 (6): 1067-1078

DOI 10. 18307/2015.0611

(C) 2015 by Journal of Lake Sciences

\title{
应用底栖动物完整性指数评价上海市河流健康"
}

\author{
熊春晖, 张瑞雷, 徐玉萍, 张 玮, 陈萍萍, 王丽卿 ${ }^{* *}$ \\ (上海海洋大学水产与生命学院,上海 201306)
}

\begin{abstract}
摘 要: 据 2011-2013 年对上海市 31 条河流底栖动物的调查结果, 对 31 个生物参数进行分布范围、判别能力以及相关 性等进行分析, 确定构建上海市河流底栖动物完整性指数 ( B-IBI) 的 4 个参数: (塞毛类动物 + 蛭纲) 数量百分比、耐污类 群分类单元数、双翅目数量百分比和集食者分类单元数百分比. 采用比值法统一量纲, 将各个生物参数分值加和得到上 海市河流 B-IBI 值. 利用构建的 B-IBI 对上海市 31 条河流健康状况进行评价, 结果表明: 31 条河流中, 有 4 条河流处于健 康状态, 8 条河流处于亚健康状态, 9 条河流处于一般状态, 8 条河流处于较差状态, 2 条河流处于极差状态; 远郊河流健康 状态最好,近郊次之,市区最差.
\end{abstract}

关键词: 底栖动物完整性指数; 大型底栖动物;城市河流;健康评价; 上海市

\section{Health assessment on rivers in Shanghai City using benthic index of biotic integrity}

XIONG Chunhui, ZHANG Ruilei, XU Yuping, ZHANG Wei, CHEN Pingping \& WANG Liqing

(College of Fisheries and Life Science, Shanghai Ocean University, Shanghai 201306, P. R. China)

\begin{abstract}
Form 2011 to 2013 , benthic macro-invertebrate assemblages were sampled from 31 rivers in Shanghai City. The analyses of the range of index value distribution, judgment ability and Pearson correlation were analyzed on 31 candidate metrics. Four biological metrics including relative percentage of Oligochaeta and Hirudinea, number of tolerant taxa, percentage of Diptera number and percentage of collector taxa richness were selected for establishing Benthic Integrated Biotic Index (B-IBI). The values of metric were calculated by ratio scoring method, and B-IBI was obtained by combining all those 4 indices. According to these established criteria, results showed that among 31 rivers of Shanghai City, 4 rivers were healthy, 4 rivers were sub-healthy, 9 rivers were good-fair, 8 rivers were fair, 2 rivers were poor. The health status was best in rural rivers, followed by suburban rivers, and worst in downtown rivers.
\end{abstract}

Keywords: Benthic Integrated Biotic Index; macrozoobenthos; urban river; health assessment; Shanghai City

河流系统是自然界最重要的生态系统之一; 河流作为营养物质的载体, 既是陆地生态系统生命的动脉, 也是水生生态系统的重要组成部分 ${ }^{[1]}$. 河流系统具有多种功能, 如泄洪、供水、输沙、景观、航运、发电等 ${ }^{[2]}$. 近年来, 随着人类活动对河流生态系统影响的加剧, 河流生态破坏日益加重 ${ }^{[3-5]}$. 因此, 对河流系统进行生态 健康评价成为国内外水域生态学研究的热点 ${ }^{[3-8]}$.

生物完整性指数 (index of biotic integrity, IBI), 常用来描述生物与非生物之间的关系 ${ }^{[9-11]}$, 并依据多个 生物参数综合反映水体的生物学状况, 进而评价河流乃至整个流域的健康状态. 最早, Karr 以鱼类为研究对 象建立生物完整性指数对河流生态系统健康进行评价 ${ }^{[10]}$, 后来逐步发展到以底栖动物 ${ }^{[12-14]}$ 、周丛生 物 ${ }^{[10,15]}$ 、浮游生物 ${ }^{[16]}$ 和高等维管束植物 ${ }^{[11]}$ 为研究对象. 美国俄亥俄州环境保护局提出的无脊椎动物指数 ( ICI), 是用一种相似的方法来评价无脊椎动物的生物完整性, 之后, 形成了在全球范围内广泛应用的底栖 动物完整性指数 (Benthic-IBI, 简称 B-IBI) ${ }^{[14]}$, 随后这种方法被美国、英国、加拿大、澳大利亚和南非等国家

* 上海市水务局 “十二五” 河道生态治理技术指南研究及编制项目 (沪水科 2011-07) 和上海市水务局重要河湖健康 评估项目联合资助. 2014-10-11 收稿;2015-03-13 收修改稿. 熊春晖 (1987～), 男, 硕士研究生; E-mail : xchshou @ hotmail. com.

** 通信作者;E-mail:lqwang@ shou. edu. cn. 
的环境保护部门广泛应用 ${ }^{[17-18]}$.

我国在 B-IBI 的研究和应用起步较晚, 最早由杨莲芳等将水质生物评价方法系统地介绍到我国 ${ }^{[19]}$. 王 备新等 ${ }^{[20]}$ 以安徽黄山地区的溪流为对象, 首次对 B-IBI 体系构建进行研究. 之后国内其他学者分别以大型 流域、湖泊水库和沿海水域为对象建立了 B-IBI 体系 ${ }^{[21-27]}$. 张远等 ${ }^{[24]}$ 和李艳利等 ${ }^{[25]}$ 分别以辽河流域和浑太 河流域为研究对象构建 B-IBI 评价体系, 对 B-IBI 指标体系的构建方法、指标选择和评价标准进行研究, 为我 国北方河流的 IBI 评价提供依据. 在国外, Morley 等 ${ }^{[28]}$ 以普吉特湾郊区河流为研究对象, 对 B-IBI 和评价标 准进行研究, 发现 B-IBI 与城市化程度呈显著负相关关系. Weigel 等 ${ }^{[29]}$ 以莫斯科中西部河流为研究对象构 建 B-IBI 体系, 结果表明 B-IBI 值的大小受人类活动的影响非常明显. 但众多研究中完全以城市河流为研究 对象构建 B-IBI 评价体系的报道比较少见.

城市河流作为一个完整的社会、经济、自然的复合生态系统, 为城市生活提供就近水源、减弱城市热岛 效应和洪涝灾害、景观多样性的组成、物种多样性保护和人类休闲娱乐都具有重要意义. 因此, 本文以上海 市具有代表性的 31 条河流为研究对象, 依据 B-IBI 的构建方法, 建立上海市河流 B-IBI 体系和评价标准, 并 对上海市河流生态系统的健康状况进行评价, 以期为上海市河流的生态修复和管理提供依据.

\section{1 研究方法}

\section{1 研究区概况}

上海是中国平原河网地区的典型城市之一, 截至 2006 年, 全市自然或人工河流已超过 33127 条(段), 全长约有 $21646.6 \mathrm{~km}^{[30]}$, 是我国水面积比重较大、河网密度较高的地区之一.

本研究分别于 2011-2013 年 5、8、11 月,选取上海市 31 条河流( 图 1) 采集底栖动物. 根据河流的长度、

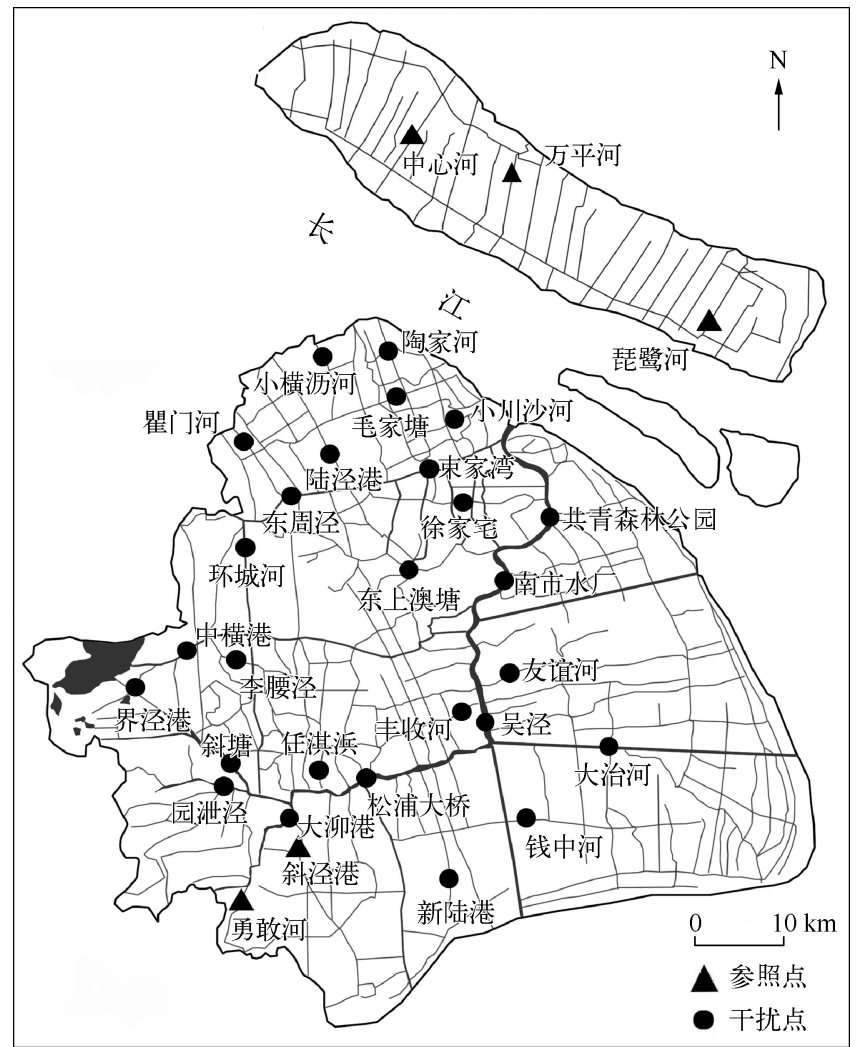

图 1 上海市调查河流分布

Fig. 1 Distribution of the sampling rivers in Shanghai City 
宽度和水深等特点在每条河流设 3 4 个采样点, 31 条河流共设 105 个采样点. 考虑到上海市河流的多样性 和土地利用类型的不同, 将 31 条河流分为 3 种类型: 一是市内 (外环路以内) 河流, 主要包括东上澳塘、徐家 宅和黄浦江下游; 二是近郊 (介于外环路与环城高速之间) 河流, 主要包括大治河、钱中河、大泖港、黄浦江中 上游等 14 条河流;三是远郊 (环城高速以外) 河流,主要包括斜塘、中横港、万平河等 14 条河流.

\section{2 样品采集与分析方法}

选用面积为 $1 / 16 \mathrm{~m}^{2}$ 改良型彼得森采泥器, 每个样点采集 2 次, 将底泥倒人 60 目的笁绢网兜内, 笁洗后 将剩余物倒人 $1 \mathrm{~L}$ 聚乙烯塑料瓶中, 用 $4 \% \sim 10 \%$ 的福尔马林溶液固定后带回实验室, 再用 80 目样篮洗去污 泥,放人白瓷盘中挑出标本, 然后在显微镜下鉴定, 标本尽量鉴定到种 ${ }^{[31-32]}$.

水质理化指标测定, 分现场和室内两部分进行: 水温 $(\mathrm{WT}) 、$ 酸碱度 $(\mathrm{pH})$ 、溶解氧 $(\mathrm{DO})$ 、电导率、盐度等 指标采用 YSI( Pro-plus) 现场测定; 透明度 (SD) 利用塞氏盘现场测定, 水深用 BW17-SFCC-手持式超声波水 深仪测定. 另采集 $1 \mathrm{~L}$ 混合水样带回实验室, 测定总磷 $(\mathrm{TP})$ 、总氮 $(\mathrm{TN})$ 、高锰酸盐指数 $\left(\mathrm{COD}_{\mathrm{Mn}}\right)$ 和叶绿素 $\mathrm{a}$ (Chl. a) 浓度等指标 ${ }^{[33]}$.

将每条河流各点调查获得的数据求平均值, 然后将 2011-2013 年 (5、8、11 月) 各河流的数据求平均值, 即将每条河流作为独立的样本进行候选生物指标的计算, 所有数据均在 Excel 2007 软件中进行预处理, 用 SPSS 19.0 软件对数据进行相关性分析, 箱型图用 Origin Pro 8.5 软件进行分析.

\section{3 参照点的确定}

参照点和干扰点的确定是建立底栖动物完整性指数及评价标准的首要条件. Morley 和 Blocksom 等按干 扰程度大小可分为无干扰样点、干扰极小样点和干扰样点 ${ }^{[34-35]}$. 由于上海市经济发达, 人口密集, 找到无干 扰样点或者干扰极小样点作为参照点很困难. 因此, 结合国内外已有的研究成果, 结合河道的实际情况确定 了参照点选择的两个原则: 一是百分比模式相似性指数 $(P M A) \geqslant 50^{[36-37]}$; 二是水质综合标准在 III 类标准以 上. 按照上述原则, 从 31 条河流中最终确定 5 条河流作为参照点, 分别是崇明岛的中心河、万平河、琵鹭河及 金山区的勇敢河和斜泾港,其余的作为干扰点.

\section{4 候选指标的篮选以及分布范围分析}

根据本研究调查数据, 参考相关文献 ${ }^{[38]}$, 选取能够代表环境变化对目标生物 (个体、种群、群落) 数量、 结构和功能产生影响的生物指标作为候选指标, 包括个体数量、分类单元数、腹足纲数量百分比、耐污类群 分类单元数、BI 值和集食者数量百分比等 31 个生物指标 (表 1 ). 然后将这些候选指标进行笁除, 对随着干 扰增强而值变小的一类指数, 如果指数值过小, 说明受干扰后的可变范围比较窄, 不宜构建 B-IBI 指数体系, 将其删除; 同理, 随着干扰增强而值变大的指数, 如果指数值过大, 也不宜构建. 另外如果指数值的标准差 大, 说明也不适宜.

\section{5 判别能力}

根据 Barbour 等 ${ }^{[39]}$ 的篮选原则和评价方法, 对所有样点的 $25 \% \sim 75 \%$ 分位数的范围进行比较, 即箱体 $I Q$ 的重叠情况, 并分别赋予不同的值. 箱体没有重叠的 $I Q$ 为 3 ; 部分重叠的, 但各自中位值都在对方箱体范 围之外的 $I Q$ 为 2 ; 仅一个中位值在对方箱体范围之内的 $I Q$ 为 1 ; 各自中位值都在对方箱体之内的 $I Q$ 为 0 . 选择 $I Q \geqslant 2$ 的参数进一步分析.

\section{6 相关性分析}

对于剩余的参数进行正态分布检验, 对于符合正态分布的生物参数进行 Pearson 相关性分析, 而不符合 的则进行 Spearman 相关性分析, 根据相关性显著水平确定生物指标间的信息重叠程度, 采用 Maxted 标准, 如果 2 个指数间显著相关, 即 $|r|>0.75$, 则表明 2 个指数间所反映的信息大部分是重叠的, 选择一个 即可 ${ }^{[39]}$.

\section{7 评价参数标准化}

目前常用的分值计算方法有 3 种: 3 分法、4 分法和比值法 ${ }^{[39]}$, 其中比值法是国内外最常用的方法. 王备 新等 ${ }^{[20]}$ 对这 3 种方法的准确性进行比较, 发现比值法明显优于其它 2 种方法. 因此, 本研究采用比值法计算 生物指数值. 具体方法是对于受到干扰越强则指数值越小的指数, 以 $95 \%$ 分位数值为最佳期望值, 各点指数 分值等于样点的指数值除以 $95 \%$ 分位数值; 对于受干扰越强则指数值越大的指数, 则以 $5 \%$ 分为数值为最佳 
期望值. 计算公式分别为:

$$
\begin{gathered}
B I_{m}=X_{m} / X_{0.95} \\
B I_{m}=\left(X_{\text {max }}-X_{m}\right) /\left(X_{\text {max }}-X_{0.05}\right)
\end{gathered}
$$

式中, $B I_{m}$ 为第 $m$ 个样点生物指数的计算分值, $X_{\text {max }}$ 为第 $m$ 个样点中的最大生物指数值, $X_{m}$ 为第 $m$ 个样点的 生物指数值, $X_{0.95}$ 为第 $m$ 个样点中的 $95 \%$ 分位生物指数值, $X_{0.05}$ 为第 $m$ 个样点中的 $5 \%$ 分位生物指数值.

表 1 构建 B-IBI 指标体系的生物参数对干扰的反应

\begin{tabular}{|c|c|c|c|}
\hline 指标类型 & 序号 & 生物参数 & 对干扰的反应 \\
\hline \multirow[t]{2}{*}{ 物种丰富度 } & M1 & 个体数量 & 增大 \\
\hline & M2 & 分类单元数(种类数) & 减小 \\
\hline \multirow[t]{16}{*}{ 种类组成 } & M3 & (甲壳动物 + 软体动物) 数量百分比 & 减小 \\
\hline & M4 & 软体动物数量百分比 & 减小 \\
\hline & M5 & 寡毛类动物数量百分比 & 增大 \\
\hline & M6 & (寡毛类动物 + 蛭纲) 数量百分比 & 增大 \\
\hline & M7 & 腹足纲数量百分比 & 减少 \\
\hline & M8 & 非昆虫类数量百分比 & 增大 \\
\hline & M9 & 双翅目数量百分比 & 减小 \\
\hline & M10 & 颤蚓目数量百分比 & 增大 \\
\hline & M11 & 摇蚊数量百分比 & 减小 \\
\hline & M12 & 软体动物分类单元数百分比 & 减小 \\
\hline & M13 & (甲壳动物 + 软体动物) 分类单元数百分比 & 减小 \\
\hline & M14 & 双翅目分类单元数百分比 & 减小 \\
\hline & M15 & 摇蚊分类单元数百分比 & 减小 \\
\hline & M16 & 寡毛类动物生物量百分比 & 增大 \\
\hline & M17 & 软体动物生物量百分比 & 减小 \\
\hline & M18 & 水丝蚓生物量百分比 & 增大 \\
\hline \multirow[t]{7}{*}{ 生物耐受性 } & M19 & 耐污类群 (PTV 7) 分类单元数 & 增大 \\
\hline & M20 & 兼性类群 $(3<P T V<7)$ 分类单元数 & 减小 \\
\hline & M21 & 耐污类群数量百分比 & 增大 \\
\hline & M22 & 兼性类群数量百分比 & 减小 \\
\hline & M23 & 耐污类群分类单元数百分比 & 增大 \\
\hline & M24 & 兼性类群分类单元数百分比 & 减小 \\
\hline & M25 & $B I$ 指数值 & 减小 \\
\hline \multirow[t]{6}{*}{ 营养结构 } & M26 & 集食者数量百分比 & 增大 \\
\hline & M27 & 刮食者数量百分比 & 减小 \\
\hline & M28 & 集食者分类单元数 & 增大 \\
\hline & M29 & 刮食者分类单元数 & 减小 \\
\hline & M30 & 集食者分类单元数百分比 & 增大 \\
\hline & M31 & 刮食者分类单元数百分比 & 减小 \\
\hline
\end{tabular}

Tab. 1 Candidate biological metrics for B-IBI and their expected direction of response to disturbance

\section{8 健康评价标准}

将计算后的指数分值求和, 即获得 B-IBI 指数值. 界定河流健康与非健康的标准是参照点底栖动物生物 完整性指数值的 $25 \%$ 分位值, 如果样点 B-IBI 大于参照点 B-IBI 的 $25 \%$ 分位值, 则说明该样点相对健康, 其 所受到的人类干扰相对较小; 而对 B-IBI 值小于参照点 B-IBI 值的 $25 \%$ 分位数值的样点, 则利用四等分法将 0 到参照点 $25 \%$ 分位值之间的范围分为 4 等分, 即健康、亚健康、一般、较差、极差 5 个等级. 


\section{2 结果与分析}

本研究 9 次调查共采集底栖动物 71 种, 隶属于 3 门 7 纲 27 科, 其中软体动物门 2 纲 8 科 22 种, 占总种 数的 $31 \%$; 环节动物门 3 纲 9 科 19 种, 占总种数的 $26.8 \%$; 节肢动物门 2 纲 10 科 30 种, 昆虫纲 21 种, 占总 种数的 $29.5 \%$,甲壳纲 9 种, 占总种数的 $12.7 \%$.

\section{1 分布范围分析}

计算 31 个生物参数在 4 个参照点的分布情况, 即 $25 \% \sim 75 \%$ 分位数的标准差太大以及分布范围太大或 者太小的参数都不适宜构建 B-IBI 指数. 通过分析表明: M2、M3、M4、M7、M12、M13、M14、M15、M27 和 M31 这 10 个生物参数随着干扰强度的增强, 其值的可变动范围非常窄, 因此, 不合适参与构建 B-IBI 指标体系. 而 M1 标准差过大, 同样不考虑 (表 2). 对剩余的 20 个生物参数进行进一步分析.

表 231 个生物参数值在 5 个参照点中的分布情况

Tab. 2 Distribution of 31 metrics values from 5 reference sites

\begin{tabular}{|c|c|c|c|c|c|c|c|}
\hline 生物参数 & 平均值 & 标准差 & 最大值 & 最小值 & $25 \%$ 分位值 & 中位值 & $75 \%$ 分位值 \\
\hline M1 & 513.15 & 613.54 & 1603.33 & 137.90 & 239.17 & 247.33 & 338.00 \\
\hline M2 & 7.28 & 0.80 & 8.67 & 6.67 & 6.83 & 7.00 & 7.25 \\
\hline M3 & 0.11 & 0.11 & 0.30 & 0.04 & 0.06 & 0.07 & 0.08 \\
\hline M4 & 0.05 & 0.01 & 0.07 & 0.04 & 0.04 & 0.05 & 0.06 \\
\hline M5 & 0.43 & 0.26 & 0.85 & 0.17 & 0.32 & 0.35 & 0.46 \\
\hline M6 & 0.46 & 0.24 & 0.85 & 0.26 & 0.32 & 0.37 & 0.47 \\
\hline M7 & 0.05 & 0.02 & 0.07 & 0.03 & 0.03 & 0.04 & 0.05 \\
\hline M8 & 0.57 & 0.22 & 0.90 & 0.32 & 0.44 & 0.55 & 0.64 \\
\hline M9 & 0.43 & 0.22 & 0.68 & 0.10 & 0.36 & 0.45 & 0.56 \\
\hline M10 & 0.43 & 0.26 & 0.85 & 0.17 & 0.32 & 0.35 & 0.46 \\
\hline M11 & 0.44 & 0.21 & 0.68 & 0.13 & 0.36 & 0.45 & 0.58 \\
\hline M12 & 0.24 & 0.06 & 0.35 & 0.18 & 0.22 & 0.22 & 0.24 \\
\hline M13 & 0.28 & 0.06 & 0.37 & 0.22 & 0.24 & 0.24 & 0.30 \\
\hline M14 & 0.38 & 0.01 & 0.39 & 0.36 & 0.37 & 0.38 & 0.38 \\
\hline M15 & 0.38 & 0.01 & 0.39 & 0.36 & 0.37 & 0.38 & 0.38 \\
\hline M16 & 0.09 & 0.13 & 0.32 & 0 & 0.02 & 0.02 & 0.09 \\
\hline M17 & 0.74 & 0.21 & 0.97 & 0.49 & 0.64 & 0.68 & 0.94 \\
\hline M18 & 0.08 & 0.12 & 0.30 & 0 & 0.02 & 0.05 & 0.05 \\
\hline M19 & 5.01 & 0.91 & 6.00 & 3.67 & 4.71 & 5.00 & 5.67 \\
\hline M20 & 2.05 & 0.73 & 2.83 & 1.25 & 1.33 & 2.14 & 2.67 \\
\hline M21 & 0.88 & 0.11 & 0.97 & 0.70 & 0.87 & 0.89 & 0.96 \\
\hline M22 & 0.11 & 0.10 & 0.28 & 0.03 & 0.03 & 0.10 & 0.11 \\
\hline M23 & 0.71 & 0.10 & 0.82 & 0.55 & 0.67 & 0.70 & 0.78 \\
\hline M24 & 0.27 & 0.09 & 0.40 & 0.18 & 0.19 & 0.30 & 0.30 \\
\hline M25 & 8.47 & 0.58 & 9.04 & 7.53 & 8.42 & 8.55 & 8.80 \\
\hline M26 & 0.88 & 0.06 & 0.96 & 0.80 & 0.86 & 0.89 & 0.92 \\
\hline M27 & 0.08 & 0.06 & 0.18 & 0.03 & 0.04 & 0.05 & 0.07 \\
\hline M28 & 4.79 & 0.31 & 5.00 & 4.25 & 4.83 & 4.86 & 5.00 \\
\hline M29 & 1.56 & 0.65 & 2.67 & 1.00 & 1.29 & 1.33 & 1.50 \\
\hline M30 & 0.65 & 0.08 & 0.75 & 0.58 & 0.60 & 0.62 & 0.72 \\
\hline M31 & 0.20 & 0.09 & 0.35 & 0.12 & 0.15 & 0.16 & 0.20 \\
\hline
\end{tabular}




\section{2 判别能力分析}

根据 $I Q$ 值的评定方法, 对剩余的 20 个生物参数进行箱型图 (图 2) 分析, 结果表明: M20、M21、M22、 M23、M24、M25 和 M26 的 $I Q$ 值为 1 或 0 ,所以将其删除,剩余的 13 个生物参数进人下一步分析.
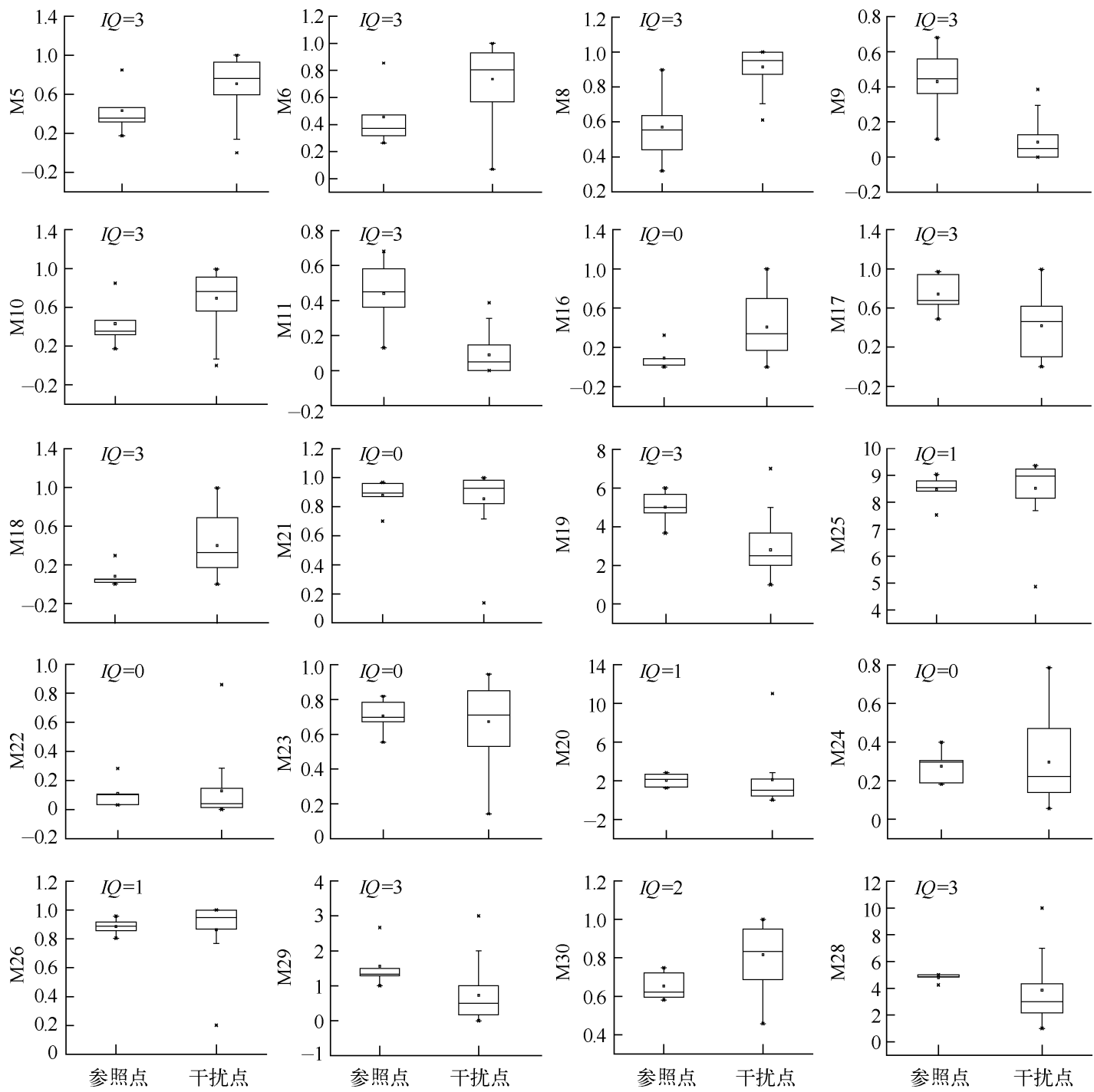

图 2 候选生物参数在参照点和干扰点的箱线图

Fig. 2 Box-plots of candidate metrics between reference and impaired sites

\section{3 相关性分析}

对剩余的 13 个生物参数进行正态分布检验,结果表明均符合正态分布,计算其 Pearson 相关系数 (表 3 ). 在反映群落种类组成中的 M5、M6、M10、M16、M17 和 M18 之间呈显著相关, 其中包含的信息重叠, 而 M6 中 包含的信息更丰富, 故保留; 同理, M8、M9 和 M11 之间呈显著相关, 保留 M9. 在反映营养结构中的 M29 和 M30 之间呈显著相关, 应保留 M30, 然而虽然 M30 与 M28 无显著相关性, 但是 M30 所含的信息包含 M28, 故 保留 M30. 在反映生物耐受性中仅剩下 M19, 虽然与 M6、M9 和 M30 之间有一定的相关性, 但 M19 是唯一保 留有关生物耐受性信息的参数, 包含生物耐受性的部分信息, 故保留. 根据以上生物指数的䇥选方法, 最终 确定 M6、M9、M19 和 M30 共 4 个生物参数作为计算 B-IBI 的指标体系. 
表 313 个生物参数间的 Pearson 相关分析结果

Tab. 3 Pearson's correlation matrix of 13 candidate metrics

\begin{tabular}{|c|c|c|c|c|c|c|c|c|c|c|c|c|c|}
\hline $\begin{array}{l}\text { 生物 } \\
\text { 参数 }\end{array}$ & M5 & M6 & M8 & M9 & M10 & M11 & M16 & M17 & M18 & M19 & M28 & M29 & M30 \\
\hline M5 & 1 & & & & & & & & & & & & \\
\hline M6 & $0.83^{* *}$ & 1 & & & & & & & & & & & \\
\hline M8 & $0.41^{*}$ & $0.48^{* *}$ & 1 & & & & & & & & & & \\
\hline M9 & $-0.41^{*}$ & $-0.48^{* *}$ & $-0.99^{* *}$ & 1 & & & & & & & & & \\
\hline M10 & $0.65^{* *}$ & $0.79^{* *}$ & $0.39^{*}$ & $-0.39^{*}$ & 1 & & & & & & & & \\
\hline M11 & $-0.40^{*}$ & $-0.47^{* *}$ & $-0.99^{* *}$ & $0.99^{* *}$ & $-0.38 *$ & 1 & & & & & & & \\
\hline M16 & $0.70^{* *}$ & $0.80^{\text {** }}$ & $0.42^{*}$ & $-0.42^{*}$ & $0.52^{* *}$ & $-0.41^{*}$ & 1 & & & & & & \\
\hline M17 & $-0.56^{* *}$ & $-0.79^{* *}$ & $-0.38^{*}$ & $0.38 *$ & $-0.55^{* *}$ & $0.38 *$ & $-0.85^{* *}$ & 1 & & & & & \\
\hline M18 & $0.70^{* *}$ & $0.79^{* *}$ & $0.43^{*}$ & $-0.43^{*}$ & $0.51^{* *}$ & $-0.42^{*}$ & $0.99^{* * *}$ & $-0.86^{* *}$ & 1 & & & & \\
\hline M19 & -0.25 & $-0.40^{*}$ & $-0.50^{* *}$ & $0.50^{\text {** }}$ & -0.30 & $0.50^{* * *}$ & $-0.56^{* *}$ & $0.62^{* *}$ & $-0.59^{* *}$ & 1 & & & \\
\hline M28 & -0.29 & $-0.43^{*}$ & 0.01 & -0.01 & -0.35 & -0.01 & $-0.38^{*}$ & $0.48^{* * *}$ & $-0.40^{*}$ & $0.52^{* *}$ & 1 & & \\
\hline M29 & $-0.47^{* *}$ & $-0.67^{* *}$ & -0.31 & 0.31 & $-0.45^{* *}$ & 0.30 & $-0.75^{* *}$ & $0.84^{* * *}$ & $-0.76^{* * *}$ & $0.57^{* * *}$ & 0.34 & 1 & \\
\hline M30 & $0.46^{* *}$ & $0.65^{* *}$ & 0.32 & -0.32 & $0.46^{* *}$ & -0.32 & $0.81^{* *}$ & $-0.79^{* *}$ & $0.81^{* *}$ & $-0.55^{* *}$ & -0.17 & $-0.83^{* *}$ & 1 \\
\hline
\end{tabular}

**表示在 0.01 水平 (双侧) 上显著相关; *表示在 0.05 水平(双侧)上显著相关.

\section{4 分值计算}

根据各生物参数值在所有样点的分布, 使用比值法计 算公式 (表 4)计算各样点的 B-IBI 值.

\section{5 确定健康评价标准}

将计算后的指数分值加和, 即得到 B-IBI 指数值. 用参 照点 $25 \%$ 分位数值作为健康标准, 大于该值的样点均为健 康状态, 小于该值的分布范围进行 4 等分, 确定上海市河流 的 B-IBI 指数值的评价标准, B-IBI > 2.69为健康, 2. 02 2.69 为亚健康, $1.35 \sim 2.02$ 为一般, $0.67 \sim 1.35$ 为较差, B-IBI $<0.67$ 为极差. 根据此评价标准, 对上海市 31 条河流

表 4 比值法计算 4 个生物参数分值的公式 Tab. 4 Formulas for calculating four biological metrics by ratio scoring method

\begin{tabular}{cc}
\hline 生物参数 & 分值计算公式 \\
\hline M6 & $(1-$ M6 $) / 0.79$ \\
M9 & M9/0.5 \\
M19 & $(7-$ M19 $) / 6$ \\
M30 & $(1-$ M30 $) / 0.46$ \\
\hline
\end{tabular}
底栖动物完整性的状况进行评价 (图 3). 结果表明:31 条河流中, 有 4 条河流处于健康状态, 占 $12.9 \% ; 8$ 条 河流处于亚健康状态, 占 $25.8 \%$; 9 条河流处于一般状态, 占 $29 \% ; 8$ 条河流处于较差状态, 占 $25.8 \% ; 2$ 条河 流处于极差状态, 占 $6.5 \%$.

上海市内的 3 条河流中有 2 条处于极差状态, 1 条处于一般状态, 可能与该地区人口密集, 受到城 市污水等点源的污染比较严重有关; 近郊的 14 条河流中有 5 条处于亚健康状态, 3 条处于一般状态, 6 条处于较差状态, 该区域健康状况有所改善, 可能与该区域河流人口密度相对于市内较小, 污染较小 有关. 远郊的 14 条河流中有 4 条处于健康状态, 3 条处于亚健康状态, 5 条处于一般状态, 2 条处于 较差状态, 相对于以上 2 个区域健康状况有所提升. 整体呈现出远郊区域河流健康好于近郊, 市内 最差.

\subsection{B-IBI 与环境因子的相关性分析}

K-S 检验结果表明,11 项理化指标均符合正态分布, 采用 Pearson 相关分析的结果 (表 5 ) 表明, B-IBI 与 $\mathrm{SD}$ 和 DO 浓度呈显著正相关 $(P<0.05)$, 与 $\mathrm{TN}$ 、TP 和 Chl. a 浓度呈显著负相关 $(P<0.05)$, 而与 $\mathrm{COD}_{\mathrm{Mn}}$ 、温 度、pH 值、水深等相关性不显著 $(P>0.05)$. SD、Chl. a TN 和 TP 浓度均是表征水体富营养化程度的重要指 标 ${ }^{[40]}$, 初步认定上海市河流 B-IBI 与水体富营养化程度呈显著相关. 


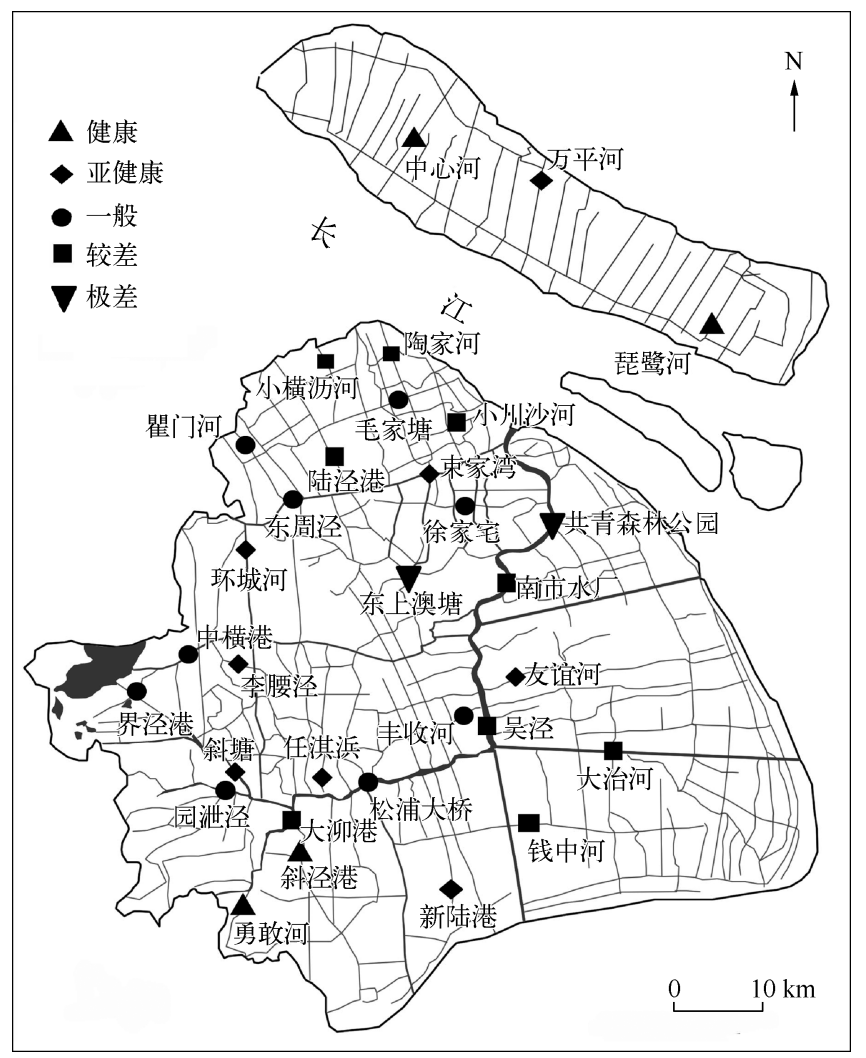

图 3 利用 B-IBI 评价上海市河流健康状况

Fig. 3 Health status of rivers in Shanghai City assessed by B-IBI

表 5 B-IBI 值与理化指标的相关系数

Tab. 5 Correlation coefficient between B-IBI and physico-chemical parameters

\begin{tabular}{ccccccccccc}
\hline $\mathrm{TN}$ & $\mathrm{TP}$ & $\mathrm{COD}_{\mathrm{Mn}}$ & $\mathrm{Chl} . \mathrm{a}$ & $\mathrm{WT}$ & $\mathrm{pH}$ & $\mathrm{SD}$ & $\mathrm{DO}$ & 盐度 & 电导率 & 水深 \\
\hline$-0.639^{* *}-0.618^{* *}$ & -0.021 & $-0.614^{*}$ & 0.085 & $0.422^{*}$ & $0.740^{* *}$ & $0.698^{* * *}$ & -0.068 & -0.058 & -0.056 \\
\hline
\end{tabular}

$* *$ 表示在 0.01 水平 (双侧) 上显著相关; *表示在 0.05 水平 (双侧) 上显著相关.

\section{7 各季度 B-|BI 体系的生物参数和健康评价标准}

通过对各季度 B-IBI 体系的构建, 结果表明构建春、夏和秋季 B-IBI 体系的生物参数均为 2 个, 春季为物 种丰富度中的 M2 和生物耐受性中的 M22, 夏季为种类组成中的 M8 和生物耐受性中的 M24, 秋季为种类组 成中的 M8 和生物耐受性中的 M23; 全年生物参数为 4 个, 分别为种类组成中的 M6 和 M9、生物耐受性中的 M19 和营养结构中的 M30. 各季节 B-IBI 健康评价标准值基本相同 (表 6 ), 春季健康标准为 $>1.08$, 夏季 为 $>1.20$, 秋季为 $>1.25$, 而全年的 B-IBI 健康评价标准则为 $>2.69$.

从构建 B-IBI 体系的生物参数看, 利用全年的数据构建 B-IBI 体系的生物参数所包含的信息要多于单个 季节生物参数; 从 B-IBI 健康评价标准看, 利用全年的数据构建的 B-IBI 体系中, 健康标准要高于单个季节.

\section{3 讨论}

\section{1 季节变化对 B-IBI 体系的影响}

在国内众多研究中, 大多数学者都依据一个季度的底栖生物对整个水域进行健康评价 ${ }^{[20-27]}$, 越来越多 的研究者意识到采用多个季节或年际间的数据, 将有助于提高所构建的完整性指数的可靠性 ${ }^{[41.44]}$. 国外 
Astin在建立河流底栖动物完整性指数时认为, 将同一监测点不同季节的数据进行合并处理是有必要的 ${ }^{[45]}$. 但 Burton 等 ${ }^{[46]}$ 和 Gerritsen 等 ${ }^{[47]}$ 研究发现不同季节单独建立一个底栖动物完整性指数没有必要, 因为春季 和秋季底栖动物样本的相似度很高.

表 6 各季节 B-IBI 评价标准

Tab. 6 Assessment criteria of B-IBI in each season

\begin{tabular}{cccccc}
\hline 季节 & 极差 & 较差 & 一般 & 亚健康 & 健康 \\
\hline 春季 & $0 \sim 0.27$ & $0.27 \sim 0.54$ & $0.54 \sim 0.81$ & $0.81 \sim 1.08$ & $>1.08$ \\
夏季 & $0 \sim 0.30$ & $0.30 \sim 0.60$ & $0.60 \sim 0.90$ & $0.90 \sim 1.20$ & $>1.20$ \\
秋季 & $0 \sim 0.31$ & $0.31 \sim 0.62$ & $0.62 \sim 0.94$ & $0.94 \sim 1.25$ & $>1.25$ \\
全年 & $0 \sim 0.67$ & $0.67 \sim 1.35$ & $1.35 \sim 2.02$ & $2.02 \sim 2.69$ & $>2.69$ \\
\hline
\end{tabular}

本研究中分别利用全年与各个季节的数据构建 B-IBI 体系, 比较发现, 利用全年数据构建的 B-IBI 体系 中生物指标所包含的信息要多于单个季节, 其健康状态的指数值大于单个季节的. 各季节的健康标准基本 相同, 健康状态的标准值都在 1.20 左右, 各季度的健康评价标准要明显高于全年的评价标准, 评价结果为 上海市河流基本处在较差和极差状态. 本研究的结果表明, 季节变动对同一水域 B-IBI 体系的生物参数构成 和健康评价标准有影响, 但本研究没有分析各个季节的底栖动物群落自然演替的差异性, 并且缺少冬季期 间对构建 B-IBI 体系的影响,所以季节变动对构建 B-IBI 体系影响的程度,有待进一步的研究.

\section{$3.2 \mathrm{~B}-\mathrm{IBI}$ 的适用性}

大型底栖动物的群落特征及空间分布与诸多环境因子具有密切关系, 所以在应用底栖动物完整性指数 评价河流健康状态时, 要注意与其他评价因子如水文、河道形态、水质理化指标相结合. Llansó 等 ${ }^{[48]}$ 指出健 康评价的最终结果应将底栖生物群落状况与主要胁迫因子联系起来, 以提高评价结果的准确性和适用性. 同时, B-IBI指数受到自然地貌的影响也比较大, 在美国马里兰州的 B-IBI 应用体系中, 就将溪流分为海岸平 原、内地平原、东部高原、山地丘陵等 4 种不同的类型 ${ }^{[49]}$. 在不同的地理区或生态区, 底栖动物的组成不同, 构建的 B-IBI 生物参数也不同, 例如王备新等 ${ }^{[20]}$ 以安徽黄山地区的溪流为对象, 构建的 B-IBI 指标体系仅适 用于长江中下游地区的溪流. 根据傅伯杰等的《中国生态区划方案》 ${ }^{[50]}$, 本研究所有样点均属于长江三角洲 城镇及城郊农业生态区, 避免因样点来自不同生态区对 B-IBI 及其评价标准的影响.

环境状况不同的水域,参照点的选择标准不同, 造成健康的评价标准也会有很大差异 (表 7). 如西苕溪溪 流属于山区溪流, 河流异质性和生物多样性较高, 水质较好, 参照点的选择标准比较高, 标准为田地土地利用 率小于 $6 \%$, 居民土地利用率小于 $0.2 \%$, 森林覆盖率大于 $90 \%$, 栖境指数大于 75 ; 然而, 辽河流域有一部分河 流位于城市, 河流受到一定程度的污染, 参照点的选择标准较低, 标准为水质在亚类标准以上, 样点上游无点污 染源, 样点周围无村庄、上游两侧 $1000 \mathrm{~m}$ 内无农田. 参照点的选择标准不同所建立的 B-IBI 健康评价标准也有 所不同, 西苕溪溪流的参照点选择标准较高, 得出健康状态的 B-IBI 值大于 0.69 , 健康评价标准较为严格; 而辽 河流域的参照点选择标准相对较低, 得出健康状态的 B-IBI 值 > 3.66 就可以, 健康评价标准较低. 本研究河流 完全属于城市内河, 受污染相对较严重, 水质大多处于 $\mathrm{IV} \sim \mathrm{V}$ 类标准, 甚至有的达到劣 $\mathrm{V}$ 类, 生物多样性较低, 底栖动物大多数都是耐污能力较强的种类 ${ }^{[54]}$, 参照点的选择标准较低, 得出的健康评价标准较低, 与实际情况 有一些差异, 但是在一定程度上还是能够反映上海市不同河流的健康状况. 不同的健康评价标准所构建的 B-IBI体系的生物参数也会有所不同, 西苕溪溪流 B-IBI 体系的生物指标分别是分类单元数、EPT 分类单元数、 鞘翅目 $\%$ 、前 3 位优势种分类单元数 $\%$ 、(纹石硪科/毛翅目) \% 、滤食者 $\%$ 和 $B I$ 指数; 安徽黄山地区溪流 B-IBI 体系的生物指标分别是总分类单元数、EPT 分类单元数、前 3 位优势种分类单元数 $\%$ 、粘附者 $\%$ 、敏感类群 $\%$ 和 $B I$ 指数; 浑太河流域 B-IBI 体系的生物指标分别是 EPT 分类单元数、优势分类单元个体相对丰度、耐污类群分 类单元数、敏感类群相对丰度和 Shannon-Wiener 多样性指数. 西苕溪溪流和安徽黄山地区溪流均位于山区, 生 物参数基本上都是由敏感类群所构成, 而浑太河流域有一部分流经城市, 部分生物指标由耐污类群所构成. 本 研究对象完全位于城市, 河流的健康受人类活动的影响比较大, 生物指标基本上与耐污类群有关, 由于大部分 河流污染较严重, 有些耐污的种类已达到了环境污染的最大限度, 导致耐污类群分类单元数降低, 干扰点的耐 
污类群分类单元数低于参照点, 造成耐污类群分类单元数随干扰的增加而降低. 如, 在 2011 年调查的参照点 中, 斜泾港的耐污类群共 4 种, 分别为霍甫水丝蚓 (Limnodrilus hoffmeisteri) 、铜锈环棱螺 (Bellamya aeruginosa)、 中国长足摇蚊 (Tanypus chinensis) 和黄色羽摇蚊 (Chironomus flaviplumus), 而干扰点李腰泾只有霍甫水丝蚓和 铜锈环棱螺 2 种, 基本上所有干扰点的耐污类群分类单元数都要少于参照点, 这与候选生物指标中给出的随 干扰增加而增加的标准不一致, 从而影响 B-IBI 体系的建立.

表 7 B-IBI 与参照点选择标准比较

Tab. 7 Comparison on B-IBI and criteria of reference

\begin{tabular}{|c|c|c|}
\hline 研究对象 & 参照点选择标准 & B-IBI 值( 比值法) \\
\hline 西苕溪溪流 ${ }^{[22]}$ & $\begin{array}{l}\text { 田地土地利用率 }<6 \% \text {, 居民土地利用率 }<0.2 \% \text {, 森林覆 } \\
\text { 盖率 }>90 \% \text {, 栖境指数 }>75\end{array}$ & $\begin{array}{l}\text { B-IBI }>0.69 \text { 为健康, } 0.52 \sim 0.68 \text { 为亚健 } \\
\text { 康, } 0.35 \sim 0.51 \text { 为一般, } 0.18 \sim 0.34 \text { 为 } \\
\text { 差, B-IBI }<0.17 \text { 为极差 }\end{array}$ \\
\hline 温榆河 [51 ] & $\begin{array}{l}\text { 样点上游无农作物和居民居住点, 森林覆盖率 } 90 \% \text { 以上; } \\
\text { 明显受人类活动干扰迹象, 其上游无点污染源, 且上下游 } \\
5 \mathrm{~km} \text { 之内无村庄,两侧 } 100 \mathrm{~m} \text { 宽、5 } \mathrm{km} \text { 长的范围内无农田 } \\
\text { 且有较好的沿岸植被带 }\end{array}$ & $\begin{array}{l}\text { B-IBI }>1.82 \text { 为健康, } 1.37 \sim 1.82 \text { 为亚健 } \\
\text { 康, } 0.91 \sim 1.37 \text { 为一般, } 0.45 \sim 0.91 \text { 为 } \\
\text { 差, B-IBI }<0.45 \text { 为极差 }\end{array}$ \\
\hline 浑太河流域 [25] & $\begin{array}{l}\text { 综合水质等级在 II 级以上, 栖息地评价分值在 } 150 \text { 分以 } \\
\text { 上,且河岸缓冲带土地利用无农田 }\end{array}$ & $\begin{array}{l}\mathrm{B}-\mathrm{IBI}>2.62 \text { 为健康, } 2.03 \sim 2.62 \text { 为亚健 } \\
\text { 康, } 1.56 \sim 2.03 \text { 为一般, } 1 \sim 1.56 \text { 为差, } \\
\text { B-IBI }<1 \text { 为极差 }\end{array}$ \\
\hline 辽河流域 ${ }^{[24]}$ & $\begin{array}{l}\text { 水质在 III 类标准以上, 样点上游无点污染源, 样点周围无 } \\
\text { 村庄、上游两侧 } 1000 \mathrm{~m} \text { 内无农田 }\end{array}$ & $\begin{array}{l}\text { B-IBI }>3.66 \text { 为健康, } 2.75 \sim 3.66 \text { 为亚健 } \\
\text { 康, } 1.83 \sim 2.75 \text { 为一般, } 0.92 \sim 1.83 \text { 为 } \\
\text { 差, B-IBI }<0.92 \text { 为极差 }\end{array}$ \\
\hline 太湖流域 ${ }^{[52]}$ & $\begin{array}{l}\text { 大型底栖动物多样性指数的评判标准 ( Shannon-Wiener 多 } \\
\text { 样性指数 }>3 \text {, Margalef 多样性指数 }>3 \text {, Simpson 多样性指 } \\
\text { 数 }>6 \text { ) }\end{array}$ & $\begin{array}{l}\text { B-IBI }>3.04 \text { 为健康, } 2.28 \sim 3.04 \text { 为亚健 } \\
\text { 康, } 1.52 \sim 2.28 \text { 为一般, } 0.76 \sim 1.52 \text { 为 } \\
\text { 差, B-IBI }<0.76 \text { 为极差 }\end{array}$ \\
\hline 滇池流域 ${ }^{[53]}$ & $\begin{array}{l}\text { 附近无村庄和农田、植被覆盖率高且环境受到人为保护、 } \\
\text { 污染小的水源地为参照点 }\end{array}$ & $\begin{array}{l}\text { B-IBI }>1.62 \text { 为健康, } 1.03 \sim 1.62 \text { 为亚健 } \\
\text { 康, } 0.31 \sim 1.03 \text { 为一般, } 0.10 \sim 0.31 \text { 为 } \\
\text { 差, B-IBI }<0.10 \text { 为极差 }\end{array}$ \\
\hline 上海市河流 & $\begin{array}{l}\text { 百分比模式相似性指数 }(P M A) \geqslant 50 \text {; 水质综合标准在 III类 } \\
\text { 标准以上 }\end{array}$ & $\begin{array}{l}\text { B-IBI }>2.69 \text { 为健康, } 2.02 \sim 2.69 \text { 为亚健 } \\
\text { 康, } 1.35 \sim 2.02 \text { 为一般, } 0.67 \sim 1.35 \text { 为 } \\
\text { 差, B-IBI }<0.67 \text { 为极差 }\end{array}$ \\
\hline
\end{tabular}

综上所述,不同研究对象的栖息环境不同,构建 B-IBI 体系时参照点的选择标准也不同,造成健康评价 体系的生物参数和标准也会有所不同. 这种差异性使 B-IBI 的应用受到一定的限制, 某一研究水体所构建的 B-IBI 体系只能应用于与该研究对象环境状况类似的地区, 不同环境状况的水域需要构建符合该地区的 B-IBI体系, 从而更加准确地评价河流的健康状况. 所以在应用 B-IBI 指数评价城市内河健康时, 不但要选择 更加合适的参照点, 而且要考虑到随着干扰强度的加强对生物指标的影响趋势, 从而建立更加符合本地区 的 B-IBI 体系. 另外, 本研究对上海市河流 B-IBI 和水环境因子之间的关系进行初步分析, 得出评价结果与水 质具有显著的相关性, 初步推断该地区河流 B-IBI 与水体富营养化有关. 水体较高程度的富营养化使得水质 变差,底栖动物敏感种类减少,生物完整性下降,可能对构建 B-IBI 体系有一定的影响.

致谢: 感谢中国科学院南京地理与湖泊研究所蔡永久助理研究员在论文修改方面给予极大的指导和帮助.

\section{4 参考文献}

[ 1 ] 董哲仁.生态水工学探索. 北京:中国水利水电出版社,2007:49.

[2] 倪晋仁, 崔树涁,李天宏等. 论河流生态环境需水. 水利学报,2002,(9):14-19.

[ 3 ] 唐 涛,蔡庆华,刘建康. 河流生态系统健康及其评价. 应用生态学报, 2002,13(3):1191-1194.

[ 4 ] Pinto U, Maheshwari BL. River health assessment in pen-urban landscapes: An application of multivariate analysis to identify the key variables. Water Research, 2011, 45(13) : 3915-3924. 
[ 5 ] 赵彦伟,杨志峰. 城市河流生态系统健康评价初探. 水科学进展, 2005,16(3):349-355.

[ 6 ] Norris RH, Thoms MC. What is river health? Freshwater Biology, 1999, 41(2) : 197-209.

[ 7 ] 张风玲, 刘静玲, 杨志峰. 城市河湖生态系统健康评价——北京市 “六海” 为例. 生态学报, 2005, 25 (11): 3019-3027.

[ 8 ] Johnson RK, Hering D, Furse MT et al. Indicators of ecological change: comparison of the early response of four organism groups to stress gradients. Hydrobiologia, 2006, 566(1) : 139-152.

[ 9 ] Karr JR. Assessment of biotic integrity using fish communities. Fisheries, 1981, 6 (6) : 21-27.

[10] Karr JR. Defining and assessing ecological integrity: beyond water quality. Environmental Toxicology and Chemistry, $1993, \mathbf{1 2}(9)$ : 1521-1531.

[11] Karr JR. Ecological integrity and ecological health are not the same. In: Schulze P ed. Engineering within ecological constraints. Washington DC: National Academy Press, 1995: 97-109.

[12] Karr JR, Chu EW. Sustaining living rivers. Hydrobiologia ,2000, 422/423:1-14.

[13 ] Karr JR, Rossano EM. Applying public health lessons to protect river health. Ecology and Civil Engineering, 2001 ,4(1): 3-18.

[14] Kerans BL, Karr JR. A benthic index of biotic integrity (B-IBI) for rivers of the Tennessee Valley. Ecological Applications, 1994, 4(4) : 768-785.

[15] Griffith MB, Hill BH, McCormick FH et al. Comparative application of indices of biotic integrity based on periphyton, macroinvertebrates and fish to southern Rocky Mountain streams. Ecological Indicators, 2005, 5(2) : 117-136.

[16] Eugene AS, Oh IH. Aquatic ecosystem assessment using exergy. Ecological Indicators, 2004, 4(3) : 189-198.

[17] Wright JF, Sutcliffe DW, Furse MT. Assessing the biological quality of fresh waters: RIVPACS and other techniques. Freshwater Biological Association, 2000, 46(10):1425-1427.

[18] Smith MJ, Kay WR, Edward DHD et al. AusRivAS: Using macroinvertebrates to assess ecological condition of rivers in western Australia. Freshwater Biology, 1999, 41(2): 269-282.

[19］杨莲芳,李佑文.九华河水生昆虫群落结构和水质生物评价. 生态学报, 1992,12(1):8-15.

[20］王备新,杨莲芳, 胡本进等. 应用底栖动物完整性指数 B-IBI 评价溪流健康. 生态学报, 2005,25(6):1481-1490.

[21] 池仕运, 竺维佳, 施练东等. 应用底栖动物完整性指数评价水源地水库溪流健康状态. 水生态学杂志, 2012,33(2): $16-25$.

[22] 李 强, 杨莲芳, 吴 璟等. 底栖动物完整性指数评价西苕溪溪流健康. 环境科学, 2007,28(9):2141-2147.

[23] 蔡 琨, 张 杰, 徐兆安等. 应用底栖动物完整性指数评价太湖生态健康. 湖泊科学, 2014, 26 (1): 74-82. DOI 10. $18307 / 2014.0109$.

[24] 张 远, 徐成斌,马溪平等. 辽河流域河流底栖动物完整性评价指标与标准. 环境科学学报, 2007,27(6): 919-927.

[25] 李艳利, 徐宗学, 杨晓静. 基于底栖动物完整性指数的浑太河流域河流健康状况评价. 北京师范大学学报: 自然科 学版,2013,49(2):297-303.

[26] 徐梦佳,朱晓霞,赵彦伟等. 基于底栖动物完整性指数 (B-IBI) 的白洋淀湿地健康评价. 农业环境科学学报, 2012, 31(9) : 1808-1814.

[27] 蔡立哲. 海洋底栖生物生态学和生物多样性研究进展. 厦门大学学报: 自然科学版, 2006,45 (A2) : 83-89.

[28] Morley SA, Karr JR. Assessing and restoring the health of urban streams in the puget sound basin. Conservation Biology, 2002, 16(6): :1498-1509.

[29] Weigel BM, Henne LJ, Martínez-Rivera LM. Macroinvertebrate-based index of biotic integrity for protection of streams in west-central Mexico. Journal of the North American Benthological Society, 2002 ,21(4):686-700.

[30］桑保良.上海市平原河网地区的水土流失及其治理. 中国水土保持,2003,(1):22-23.

[31] 刘月英,张文珍,王跃先等. 中国经济动物志. 北京:科学出版社,1979:134.

[32] 王洪铸. 中国小蚂类研究. 北京: 高等教育出版社,2002:228.

[33］ GB/T 3838-2002. 中华人民共和国地表水环境质量标准.

[34 ] Blocksom KA, Kurtenbach JP, Klemm DJ et al. Development and evaluation of the lake macroinvertebrate integrity index ( LMII) for New Jersey lakes and reservoirs. Environmental Monitoring and Assessment, 2002, 77(3) : 311-333.

[35] Morley SA, Karr JR. Assessing and restoring the health of urban streams in the Puget Sound Basin. Conservation Biology, 2002, 16(6) : 1498-1509. 
[36] Novak MA, Bode RW. Percent model affinity : a new measure of macroinvertebrate community composition. Journal of the North American Benthological Society, 1992, 11 (1):80-85.

[37] Barton D. The use of Percent Model Affinity to assess the effects of agriculture on benthic invertebrate communities in headwater streams of southern Ontario, Canada. Freshwater Biology, 1996, 36(2) : 397-410.

[38] 廖静秋, 黄 艺. 应用生物完整性指数评价水生态系统健康的研究进展. 应用生态学报,2013,24(1):295-302.

[39] Barbour MT, Gerritsen J, Griffith GE et al. A framework for biological criteria for Florida streams using benthic macroinvertebrates. Journal of the North American Benthological Society, 1996,15(2) : 185-211.

[40] 王 珺, 裴元生, 杨志峰. 营养盐对白洋淀草型富营养化的驱动与限制. 中国环境科学, 2010,30(S1):7-13.

[41] JoãoFeio M, Reynoldson TB, Graça MA. Effect of seasonal changes on predictive model assessments of streams water quality with macroinvertebrates. International Review of Hydrobiology, 2006, 91 ( 6 ) : 509-520.

[42] Leung ASL, Li AOY, Dudgeon D. Scales of spatiotemporal variation in macroinvertebrate assemblage structure in monsoonal streams: the importance of season. Freshwater Biology, 2012, 57 (1) : 218-231.

[43] Oliveira RBS, Baptista DF, Mugnai R et al. Towards a rapid bioassessment protocol for wadeable streams in Brazil: development of a multimetric index based on benthic macroinvertebrates. Ecological Indicators, 2011, 11(6) : 1584-1593.

[44] Bailey RC, Scrimgeour G, Coté D et al. Bioassessment of stream ecosystems enduring a decade of simulated degradation: lessons for the real world. Canadian Journal of Fisheries and Aquatic Sciences, 2012, 69(4) : 784-796.

[45] Astin LE. Data synthesis and bioindicator development fornontidal streams in the interstate Potomac River basin, USA. Ecological Indicators, 2006, 6(4) : 664-685.

[46] Burton J, Gerritsen J. A stream condition index for Virginia non-coastal streams. Virginia Department of Environmental Quality, Richmond, Virginia, USA, $2003: 163$.

[47] Gerritsen J, Carlson RE, Dycus DL et al. Lake and reservoir bioassessment and biocriteria: Technical guidance document. Washington, DC: US Environmental Protection Agency, Office of Water, $1998: 202$.

[48] Llansó RJ, Dauer D, Vølstad JH. Assessing ecological integrity for impaired waters decisions in Chesapeake Bay, USA. Marine Pollution Bulletin, 2009 , $59(1 / 2 / 3): 48-53$.

[49] Southerland MT, Rogers GM, Klien MJ et al. Improving biological indicators to better assess the condition of streams. Ecological Indicators, 2007, 7 (4):751-767.

[50] 傅伯杰,刘国华,陈利顶等. 中国生态区划方案. 生态学报,2001,21(1):1-6.

[51] 杨 柳, 李泳慧, 王俊才等. 基于 B-IBI 指数的温榆河生态健康评价. 生态学报,2012,32(11):3313-3322.

[52] 高 欣, 牛翠娟, 裴雪娇. 太湖流域大型底栖动物生物完整性研究. 北京师范大学学报: 自然科学版, 2012, 48 (4): 392-398.

[53] 苏 玉, 曹晓峰, 黄 艺. 应用底栖动物完整性指数评价滇池流域人湖河流生态系统健康. 湖泊科学, 2013, 25 (1): 91-98. DOI 10. 18307/2013. 0112.

[54] 陈小华, 高 伟, 刘文亮等. 平原河网地区大型底栖动物群落结构及其与环境因子的关系. 生态环境学报,2013,22 (8) : 1310-1316. 